\title{
Catriona Robinson
}

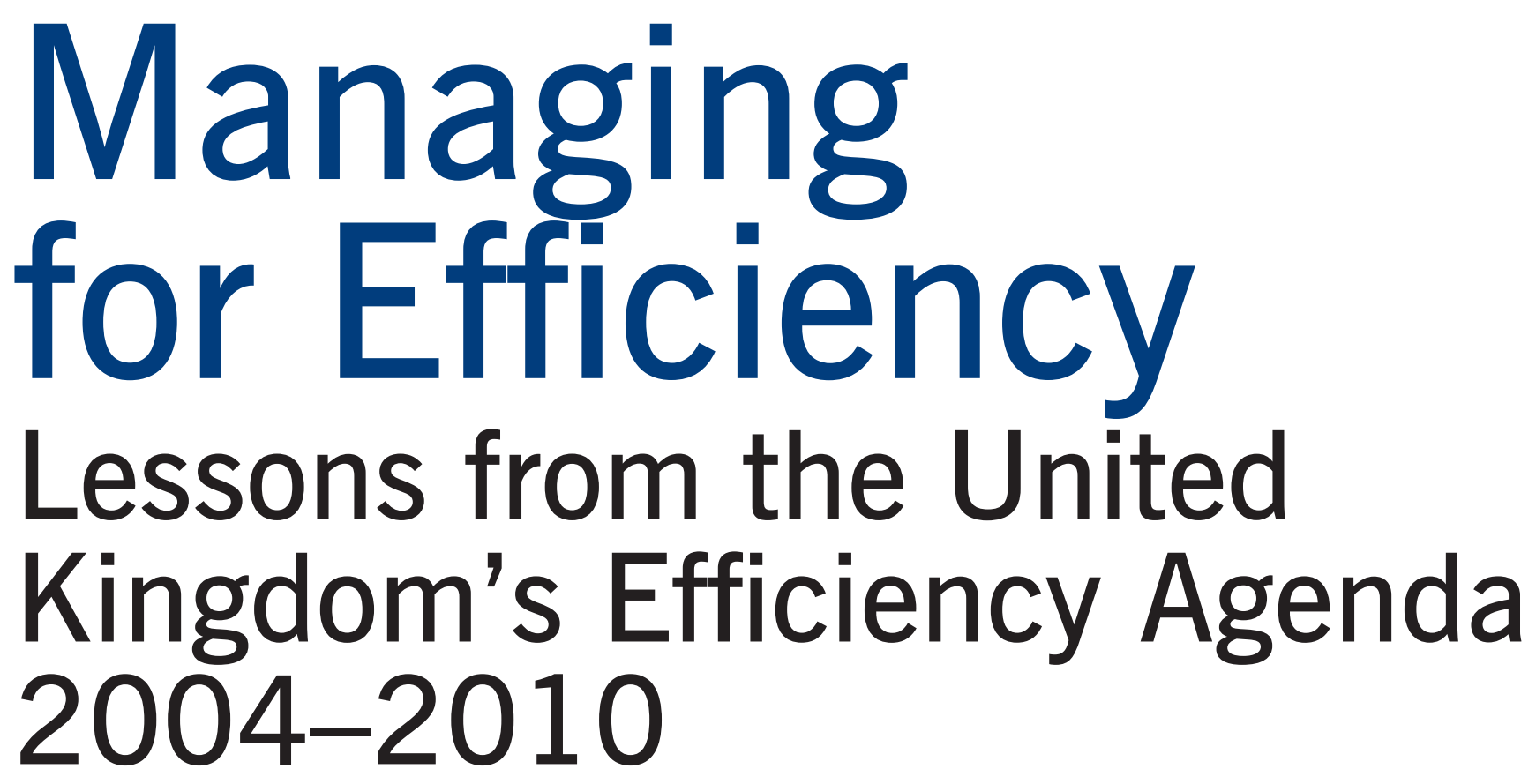

Introduction

The call for greater efficiency in public spending is not new, but today has additional force: how can we deliver more for (even) less? A combination of high public expectations about service quality and prolonged fiscal constraint requires New Zealand government departments to focus on the highest spending priorities, find more innovative ways to deliver services, and create efficiencies wherever possible (State Services Commission, 2010a, 2010b). The urgent need to refocus on providing smarter, better public services for less was a consistent theme over the past few years in public statements made by the previous secretary to the Treasury, John Whitehead. Whitehead identified developments in the

Catriona Robinson holds an MA and an MPM, both from Victoria University of Wellington. She now works for the Government Communications Security Bureau (GCSB). As the head of GCSB's Office of the Director, she has responsibility for strategy, policy and relationships. public sector in the United Kingdom as a potential model for New Zealand, particularly the speed with which 'new thinking [was] converted into action' in the pursuit of efficiency (Whitehead, 2010), and referenced in particular a programme launched in the UK in 2004 as an innovative public reform initiative from which New Zealand might learn (Whitehead, 2009a).

The dissertation on which this article is based (Robinson, 2010) considered some applicable lessons from the implementation of the efficiency agenda to which Whitehead referred. ${ }^{1}$ The focus was on four major aspects of the reform agenda:

- central control of the reform programme

- targets as a performance management tool

- quality of performance data; and

- leadership issues.

Much further work could be done, for example on the use of e-government and 
other IT initiatives in securing efficiency savings, but these fall outside the scope of this article.

The Blair-Brown administration of 1997-2010 was strongly results-focused, and introduced a number of public sector financial management reforms, which put the UK among world leaders at the time (Scheers, Sterck and Bouckaert, 2005). Following a number of smaller initiatives to improve value for money incrementally, Sir Peter Gershon $^{2}$ was asked in 2003 to conduct a review of public sector operations across government and to make which aimed to continue the impetus of the original efficiency reform agenda. This introduced a Value for Money programme (VfM), setting out new targets to be achieved between the end of Gershon programme and 2010-11 with the intention of achieving a further $\mathfrak{E}_{35}$ billion in efficiency savings.

The Labour administration was replaced in May 2010 by a ConservativeLiberal Democrat coalition with its own efficiency agenda. The coalition announced an end to Labour's focus on centrally-mandated efficiency targets in favour of reducing waste and improving

\section{The central control initially exerted by the Treasury had enabled much better coordination of the programme, albeit by significantly increasing the administrative and reporting burden on departments.}

recommendations about expenditure and efficiency. His report (Gershon, 2004) proposed specific areas in which efficiency savings could be made, and urged that a culture of efficiency should be instilled throughout the public sector. A new efficiency programme, based on Gershon's findings, was announced to begin in April 2005. It aimed to achieve $\mathfrak{E} 21.5$ billion of efficiency gains by 200708. ${ }^{3}$ Departments were each assigned an efficiency target and responsibility for apportioning the target across a range of projects. ${ }^{4}$ The programme was regarded as more broadly-based, and more ambitious, than any previous attempt to tackle efficiency in the British government sector. In the complexity of the reform agenda, in the universality of its aims, and in the close personal attention paid to it by both Prime Minister Tony Blair and Chancellor of the Exchequer Gordon Brown, this was a new, and unique, public management reform initiative for the UK (PAC, 2006, Q.15).

In 2007, Brown published a Comprehensive Spending Review, procurement, and it set up a new Efficiency Reform Advisory Group. The close of the Labour era therefore provides a tidy end point to the efficiency reform issues considered in this article.

\section{Central control}

In initiating its efficiency programme, the Labour government was explicit about the need to incentivise the public sector towards greater efficiency (Gershon, 2004). Targets were already being used by the administration as a key tool to motivate the public sector to pursue its most highly prioritised objectives with the rigour desired (Mandelson, 2010). Using targets to reinforce the importance of the efficiency objectives would thus have been natural. According to the then chair of the PAC, Tony Wright, the prime minister firmly believed that it was wrong to have permanent secretaries operating independently, without strong central control, and that accountability and improvement of standards should be driven from the centre. The deployment of centrally-imposed targets to effect the efficiency agenda gave rise, however, to what Wright described as an 'endemic tension' between the strong control exerted by the centre, as a means of enforcing progress towards a coherent and coordinated set of efficiency goals, and departments' concern that a too-controlling centre interfered unnecessarily with their capacity to run their own business in pursuit of those same goals (Lawson, 2009). This is broadly consistent with developments throughout the OECD during the period, where efforts in other jurisdictions to decentralise power had exacerbated problems of public sector coordination and coherence (Peters, 2008).

The extent to which central control was exerted varied as the efficiency programme progressed, with greater latitude for departments being permitted in the later VfM iteration. This was the result of a deliberate trade-off decision by the Treasury, to assuage departmental concerns that it had been interfering in 'every nook and cranny of every department' in their management of their efficiency targets (PAC, 2010b, Qq26, 34). Neither approach was ideal, however. The central control initially exerted by the Treasury had enabled much better coordination of the programme, albeit by significantly increasing the administrative and reporting burden on departments. VfM provided more scope for departments to manage their own affairs without Treasury involvement, but this meant that the Treasury now also had to rely on departments to ensure that published savings would stand up to scrutiny and that programmes were on track.

The efficiency agenda was taken extremely seriously by both the prime minister and the chancellor. This was emphasised by the comparatively rare combined approach to management of the programme by the two, who were more accustomed to running their priority objectives in parallel (Mandelson, 2010). Both insisted on being briefed personally and regularly on progress against efficiency targets. This close political attention can be expected to have created additional pressure for officials; it certainly would have been a strong motivator for department 
heads to ensure that successes could be reported swiftly - and, doubtless, that failings did not lead to adverse attention. The National Audit Office (NAO) reported early on that the six-monthly progress reports to the prime minister and chancellor were 'ensuring that efficiency remains a priority for senior management in departments' (NAO, $2006,7)$. But preparing regular briefs at this level represents a substantial burden for those from whom the data must be sourced; feedback from departments and central agencies alike suggested that finding the balance between appropriate levels of reporting to meet ministerial requirements and not overburdening departments was not easy.

Departments had not previously been involved in such a complex or wide-ranging programme, and looked to central bodies for guidance. An efficiency team within the Treasury was set up for this purpose but struggled, particularly early on. Frequent turnover of key personnel affected its ability to help departments grapple with the complexities of the new programme, and hindered the team in winning departments' trust to allow operating as the 'critical friend' that had been envisaged (NAO, 2006, 6). Departments found themselves, for example, instructing their relationship managers instead of the other way round: 'At the beginning it seemed they were coming and going every month ... [I]t would be really helpful to have someone with a consistent view of the old stories' (NAO, 2006, 48). Had the importance of a stable efficiency team been recognised, more could perhaps have been done to prioritise forward planning by staff.

There was also a difference of opinion between the centre and departments about the use - and usefulness - of relevant guidelines. Departments complained that long delays in publishing guidelines jeopardised effective delivery (NAO and Audit Commission, 2006), and expressed concern that at least one Treasury-approved methodology for measuring savings was not robust enough to produce defensible reporting (NAO, 2010b). Central agencies, meanwhile, felt that formal guidance was often disregarded. The Treasury, for example, had produced a 'clear and comprehensive framework' for measuring efficiencies, but assessed that departments were not applying it effectively and therefore remained weak in a number of key areas (PAC, 2007, 2008).

A good dialogue did develop at senior levels between the Treasury's Office of Government Commerce and the permanent secretaries of key departments. This close dialogue was credited with the openness with which, for example, the Department for Work and Pensions had felt prepared to disclose to the Treasury certain shortcomings regarding the calculation
Professor Christopher Hood of Oxford University argues that the 'element of terror' involved in the targets in UK public sector management made it a 'distant cousin' of the system in the USSR (Hood, 2006, 515; Bevan and Hood, 2006, 517). According to Hood, those responsible for delivering against targets were incentivised to do so by strong concern about what would happen to under-performers. He notes regular gallows humour references to a 'hanging admirals' culture, ${ }^{5}$ or to 'P45 targets', and posits widespread expectations among senior officials that the penalties for failing to meet targets would be severe, perhaps even entailing job loss

\section{Professor Christopher Hood of Oxford University argues that the 'element of terror' involved in the targets in UK public sector management made it a 'distant cousin' of the system in the USSR}

of its efficiency baseline, thereby enabling swift action and rectification (PAC, 2007). There is evident value in building relationships which facilitate this degree of trust, although of course they require resourcing, commitment and time if they are to develop effectively.

\section{Targets and incentives}

The use of targets and performance indicators to steer the behaviour of the public sector and assert control had been much advocated in Western countries from the 1980s onwards (see, for example, Pollitt, 1986 and Carter et al., 1995). In the UK, the implementation of the efficiency agenda primarily used the same quantitative, time-limited targets for controlling and monitoring departmental performance as had been a key factor of UK public management since the late 1990s.

This approach obviously relies for its effectiveness on the extent to which departments are motivated to comply.
(Hood, 2006, 2007; Hood, Emmerson and Dixon, 2009).

These assumptions were probably exaggerated. The summary dismissal of senior officials is generally not easy to accomplish, and, despite seeming agreement about a ' $\mathrm{P} 45$ targets' system, there is no evidence to suggest a significant increase in the incidence of sackings or other similarly severe forms of punishment among senior UK civil servants at any stage after targets were introduced - such as should certainly have been expected if the penalties for failure were as harsh as popularly supposed. Nor, in fact, were there any formal or legal sanctions available to ministers or to the Treasury if departments did not fulfil their objectives (Hood 2006; Norman, 2008). To an extent, though, whether or not officials' belief in the willingness of their masters to 'hang' those who failed them had any basis in reality is not important. What matters is that the belief in the threat was genuine enough to have incentivised behaviours in a certain way, so that achievement of 
the targets did indeed become the highest priority of senior officials.

One of the problems in a target approach to performance management is determining whether, as well as motivating the pursuit of certain desired objectives, it is at the same time having a perverse or unintended effect by incentivising unwanted behaviours, or by disincentivising work towards nontargeted outcomes. There is a degree of risk in relying too heavily on targets to motivate performance, in that an organisation may start to treat the achievement of its targets as its raison
The Treasury and the NAO both reported that departments were consistently planning for efficiencyrelated changes that could be delivered within a three-year reporting period, rather than anything more innovative, because the latter might have taken longer than three years and would not be rewarded (see NAO, 2010b, 7, 27-9.) The efficiency programme was thereby judged to have failed to incentivise departments to take a long-term approach to tackling the efficiency challenge by focusing them too intently on their targets (PAC, 2010a).

\section{Devising good performance indicators, particularly to measure quality of service provision, is difficult; certainly harder than measuring financial data.}

\begin{abstract}
d'être and, as a result, disregard or abandon activities which do not contribute directly to them. Outcome-focused management thereby loses ground to the outputfocused, where activity can be more easily quantified.
\end{abstract}

Naturally there are circumstances where targets offer the most direct and effective way of achieving a goal. For example, it seems unlikely that a dramatic reduction in waiting times for hospital treatment in England would have come about without extremely specific targets (Hood, 2007). But there are also many UK examples of unintended consequences: such as training which was started but not necessarily completed because the target measured only commencement. Studies also suggested that departments overly focused on efficiency targets did not evaluate the impact of efficiencymotivated changes on service provision quality as experienced by clients. For example, an initiative which measured improvements in the time taken to answer ringing telephones in a customer contact centre was not able to confirm whether customers' problems were actually resolved during their first contact (PAC, 2007; for further details, see Robinson, 2010).
Spectacular results were reported for the initial tranche of efficiency targets. Against an original target of $\mathfrak{E}_{21.5}$ billion in savings over three years, the public sector achieved an impressive $\mathfrak{E} 26.5$ billion, an over-delivery of approximately $23 \%$. Every department reported that it had not only met, but in almost every case exceeded, its target. The Department for Business Enterprise and Regulatory Reform claimed efficiency savings of $71 \%$ over its original target (HM Treasury, 2009). The original targets were admittedly intended to be realistic rather than stretch goals; this may go some way to explaining why departments seem to have found it so easy not just to meet but to exceed them. But that alone cannot satisfactorily explain such a preponderance of success stories. Either the targets allocated were so easily achievable that they were meaningless, or the performance reporting was suspect (or, perhaps, both). Whatever the case, the suspicion that, as so often in an environment of high-pressure expectations, an element of gaming may have played a part in the initial selection of the targets, or in the selection and interpretation of the data used to report results, cannot be dismissed.
The NAO did not find evidence of deliberately dishonest gaming. It did, however, raise questions about calculations of efficiency gains, particularly the use of estimates and projections rather than hard data to record efficiencies, and the use of projected rather than real figures to report headcount reallocations (NAO, 2007). Meanwhile, a study of senior officials' attitudes to targets concluded that ratchet effects and other similar forms of gaming were common. The officials interviewed for the study felt that some departments would 'play the targets game to their advantage' by negotiating undemanding targets that were hard to miss. They condemned the production of fictional performance data as dishonest, but felt that achieving reportable performance improvements by redistributing service was acceptable (results reported in Hood, 2006). The responses point to a feeling, at least among senior Whitehall officials, that gaming was not insignificant; while deliberate dishonesty seems unlikely, it may be assumed that creative use of performance data and other gaming techniques may have contributed to the startlingly successful results claimed against the first tranche of the efficiency targets.

Departments appeared to struggle to realise similar levels of performance under the VfM tranche of targets as had apparently been achieved under the Gershon programme. By March 2010, two years into the programme, only $\mathfrak{E} 15$ billon of the $\mathfrak{E}_{35}$ billion total had been reported, leaving $\mathfrak{E} 20$ billion for the final year. A key difference between the former and VfM had been that, although there was more direct involvement of the central agencies under Gershon, the reporting requirements themselves were comparatively more relaxed and less complex. This was recognised and tightened up during VfM. Without being simplistic, it could be suggested that the strong pressure on departments to demonstrate quick wins against the Gershon targets, coupled with a relatively relaxed reporting environment, may have had some bearing on the disproportionately good results which departments were able to report. 


\section{Performance information}

Devising good performance indicators, particularly to measure quality of service provision, is certainly harder than measuring financial data. Effective performance measurement for efficiency programmes can be particularly elusive (Griffiths, 2006). But good performance measurement is crucial in effective performance management. Representing new territory, the efficiency agenda involved complicated reporting and accountability parameters. Accurate performance measurement, while important, was difficult, not least because departments were attempting to use long established information systems designed for other purposes to collect and analyse new and more detailed forms of data. (NAO, 2006; PAC 2006, 2010a).

Ongoing concern was expressed by the NAO, by independent commentators and by the PAC about the quality of the UK public sector's performance data (see Robinson, 2010 for details). The impact of generally poor performance information on stakeholders' capability to accurately assess the progress of the efficiency programme was frequently identified as a major issue. Indeed, the PAC repeatedly queried whether any reliance could be put on any of the efficiency claims made by departments, or by Treasury on their behalf (PAC, 2006, 2010).

Despite the highly controlled way in which the programme was run, it must have been difficult to accurately gauge the real success of the efficiency projects given a lack of robust performance data. It is hardly a surprise, however, noting the high political importance assigned to success, that where performance data was unreliable or incomplete there should be strong motivation to put the best possible reflection on whatever data was available. It also seems likely that decisions in managing the programme must sometimes have been made on the basis of old or unreliable data.

Many efficiency projects were not stand-alone initiatives, which made it more difficult to capture the overall benefits brought about by changes in one area. For example, in its service improvement project, the Department of Health set out to measure efficiency gains from certain improvements in patient care. Accurate

performance reporting would have had to take account of the complex network of relationships within the National Health Service, the continuous changes to the various patient services offered, and the requirement for ongoing new investment. Attempting to capture accurately the real relationships between inputs and outputs proved complicated and hard to quantify for several departments. In some cases, efficiency gains were being realised only after many years of investment in complex programmes with many benefits, some not associated with the efficiency projects themselves (NAO, 2007).

\section{The goal was never just to save cash, but rather to instil such a commitment to efficiency in public sector culture that it became 'absolutely embedded in the DNA of how departments do their business' ...}

\section{Leadership}

Some of the deficiencies identified in implementing the efficiency agenda were linked with issues of institutional capacity, such as internal capability weaknesses (especially financial expertise); poor knowledge and information management; and problems with inspiring commitment to the programme. Effective and engaged leadership is critical in building institutional capacity and making a difference in the public sector.

The efficiency agenda was introduced into a public management environment characterised by political impatience,
Management by targets or performance indicators can at times have an unintended impact on the quality of service provision. An initial sharp rise in performance may be followed by flatlining, or distortions may become evident as non-incentivised outputs receive less attention than those to which performance indicators have been assigned (Hood, Emmerson and Dixon, 2009). Organisations may be so focused on ascertaining whether they are achieving their objectives that they fail to collect useful data on what their clients actually want, or whether they are meeting their needs. In the UK, departments were in many cases not able to provide assurance that service quality had not deteriorated as a result of their efficiency-related reforms. Additionally, there seemed to be little or no ability to correlate the impacts of the efficiency programme across the government sector; it was hard to tell whether the activities of one department in pursuit of efficiency were undoing the work of another (by transferring demand) (NAO, 2007). pressure on departmental resources, and an anxiety on the part of the public sector leaders to produce swift success (Amman, 2006). Major change in organisational culture usually requires an incremental, cumulative approach. The prevailing culture in Whitehall at the start of the 21st century, however, does not seem likely to have rewarded a slow-and-steady approach to change. This may go some way to explaining the felt pressure to meet targets as quickly as possible, and also the lack of success in getting real culture reform to stick.

The efficiency initiative had introduced a change programme as complex as any seen before, anticipating both structural and cultural change (NAO, 2006). The goal was never just to save cash, but rather to instil such a commitment to efficiency in public sector culture that it became 'absolutely embedded in the DNA of how departments do their business' (PAC, 2006). There was a consensus that efficiency had not been the driver that it could have been, and that minds and hearts needed to change (PAC, 2010b). 
Strong strategic leadership was intended to be a key factor in changing this.

A distinct change in attitude at senior levels was certainly evident. Senior departmental officials contributed meaningfully, and demonstrated an active interest and involvement in the programme, thereby confirming to staff that this initiative was different (NAO, 2006). It may be surmised that this noticeable change in attitude may have been due, at least in part, to the prime minister's strong interest: translated as cuts or job losses (Office for Public Management, 2007).

The same study found that agencies which demonstrated high performance in achieving efficiencies were characterised by regular communication with all staff groups; openness to new ideas; and a devolved approach which allowed individual areas to come up with their own strategies within broad parameters. This was seen as being critical in winning the backing of middle managers and more junior staff. Lower-performing

\section{The ambitious attempt to combine a long-term public management reform programme with a series of short-term resource re-allocation projects essentially did not work.}

\begin{abstract}
Two years into the programme, I cannot go into any Department in Whitehall without finding that efficiency is discussed frequently, regularly and at main Board level. It is a key topic on the agenda and an essential part of the business planning process of every Department. Two or three years ago you would not have seen that in most Departments in Whitehall; it is a significant shift in attitude and culture ... All Departments are on a journey that they were not on before the Gershon Report was written. ... We would not have achieved that without an efficiency programme. (PAC, 2007, Qq14, 79)
\end{abstract}

But senior officials' engagement with the efficiency reform project was not alone sufficient to effect the fundamental changes expected in their departments. Departments reported mixed results in securing full engagement in the efficiency programme, and there was evidence that many staff viewed it as just another economy drive. A 2007 set of case studies found that frontline local government staff felt that the efficiency programme had only added to their bureaucratic burden, while efficiency to them entities, on the other hand, had generally adopted a more centralised and top-down approach, which was predominantly concerned with ensuring tight control over key efficiency-related funding and prioritisation decisions.

The culture changes which it was imagined the efficiency programme would establish will not, paradoxically, flourish under the sort of management strategies deployed to ensure that the programme demonstrated quick wins. Creativity flourishes when there is a free flow of ideas around the organisation, when there is a culture of listening and engaging with new suggestions, and when people are encouraged to join up their thinking with that of others in different parts of the organisation (Bichard, 2000). But the environment into which the efficiency agenda was introduced tended to reward performance by recognising those who had completed tasks or met targets. The task-oriented way of acting that such a system encourages is generally not conducive to fostering creativity or risk-taking (Bichard, 2000), and has been criticised for detracting from attention needed to improve the overall performance of people and organisations or to harness the energy and insights of operational staff (Haldenby et al., 2009). Targets and indicators promote adherence to established routines and organisational processes. Motivating staff to effect comprehensive culture change had been a key factor in the efficiency reform narrative, but evidently more needed to be done in enabling staff to engage more creatively with the programme for themselves, thereby beginning to embed the desired orientation towards efficiency more decisively into the culture.

\section{Conclusion}

New Zealand and the UK are ordinarily considered to have been among the leading examples of the reforms of the 1980 s and 1990s, and the UK experience in introducing a comprehensive and pangovernment efficiency reform agenda was specifically referenced by the secretary to the New Zealand Treasury as a valuable lesson for New Zealand (Whitehead, 2009a). Although different in scale, the two nations share some important institutional characteristics in executive government. New Zealand does not, perhaps, have the same degree of strong central control over the public sector as was evident during the Blair-Brown administration: central agencies are described as having rather to 'cajole, nudge [and] inspire' departments into implementing new initiatives (Norman, 2006). As in the UK, however, the variable quality of performance information and reporting (which has already been identified as an issue on which firm action must be taken (State Services Commission, 2009, 2010a, 2010b)) would have to be addressed. Were New Zealand to follow the UK lead, meanwhile, energetic commitment from internal leadership would be very important, and thus confidence that senior officials had the necessary support for a certain amount of risk-taking in pursuit of the desired objectives (Ryan et al., 2008) would be as significant in New Zealand as in the UK context.

Efficiency reform is challenging for any administration. The Labour government in the UK made a sustained effort to make a real difference in the efficiency of the management of the UK public sector during its period in office. Its efficiency 
agenda was comprehensive in approach and complicated in operation. Progress was undeniable. Financial management capacity in public sector departments improved; some savings were certainly achieved; and improvements to both quality of services and efficiency in their provision were recorded. A genuine focus on and attention to the aims of the efficiency agenda were also noticeable (at least at senior levels).

But many of the spectacular early gains reported against efficiency targets were later dismissed as implausible. Quality of performance data was so poor that it proved unreliable in achieving the required reforms; concerns about goal displacement, gaming and other dysfunctional effects of a highly targetfocused performance management regime were also an issue. The right balance between maintaining a level of central control while permitting operational latitude in the pursuit of efficiency goals seems rarely to have been achieved.
The ambitious attempt to combine a long-term public management reform programme with a series of short-term resource re-allocation projects essentially did not work. The use of targets to achieve the programme's aims may have been a suitable approach to the latter objective, but could not incentivise the former; if anything, it stifled rather than encouraged culture change. While Gershon had initially envisaged steady rather than rapid progress towards efficiency goals as the way to ensure sustainability, this was overtaken by the political importance assigned to the programme, resulting in pressure to produce rapid wins. Ultimately, this strongly directive central oversight - which wanted to ensure that the programme was a success - was a major factor in its failure.

Coherent direction and robust oversight from the centre is of course extremely important. The UK experience teaches, however, that balance and proportionality are critical. The desire to strengthen central control cannot become so pervasive that it becomes restrictive. Flexibility and freedom extended to operational agencies will enable them to pursue efficiency objectives in a way which is relevant to local contexts, even if this involves taking risks. Achieving the right balance represents a complex set of relationships and is tricky to achieve; but is important to get right.

\footnotetext{
1 The dissertation was submitted to the School of Government, Victoria University of Wellington, in part-fulfilment of the requirements of the Master of Public Management degree, and was awarded the 2011 Holmes Prize for Public Policy. It is available from the author.

2 Then the head of the Office of Government Commerce, an independent office of the Treasury.

3 This equated to a saving of approximately $2.5 \%$.

4 Targets had mostly been discussed and agreed between departments, the Gershon review team and the Treasury prior to the launch of the efficiency programme.

5 Voltaire famously joked in the mid-18th century that in the British Navy at the time, 'From time to time they kill one of the Admirals, to encourage the others' - an indirect reference to Admiral John Byng, executed in 1756 for negligence in the performance of his duty to the Royal Navy.

6 The P45 form is issued by an employer when an employee leaves their service; the term is often used to refer to termination of employment by the employer, i.e. sacking.
}

\section{References}

Amman, R. (2006) 'The Circumlocution Office: a snapshot of civil service reform', Political Quarterly, 77 (3), pp.334-59

Bevan, G. and C. Hood (2006) 'What's Measured is What Matters: targets and gaming in the English public health care system', Public Administration, 84 (3), pp.517-38

Bichard, M. (2000) 'Creativity, Leadership and Change', Public Money and Management, 20 (2), pp.41-6

Carter, N., R. Klein and P. Day (1995) How Organisations Measure Success, London: Routledge

Gershon, P. (2004) Releasing Resources to the Frontline: independent review of public sector efficiency, London: HM Treasury

Griffiths, D. (2006), 'Some Puzzles and Paradoxes of the Efficiency Agenda - and a way forward', Public Money and Management, 26 (5), pp.313-18

Haldenby, A., P. Nolan, L. Parsons and G. Rosen (2009) The Front Line, London: Reform, http://www.reform.co.uk/portals/O/Documents/ Front\%20line\%20FINAL.pdf

HM Treasury (2009) 2009 Value for Money Update, London: HM Treasury

Hood, C. (2006) 'Gaming in Targetworld: the targets approach to managing British public services', Public Administration Review, 66 (4), pp.515-21

Hood, C. (2007) 'Public Service Management by Numbers: why does it vary? Where has it come from? What are the gaps and the puzzles?', Public Money and Management, 27 (2), pp.95-102

Hood, C., C. Emmerson and R.Dixon (2009) Public Spending in Hard Times, Oxford: University of Oxford Economic and Social Research Council, Public Services Programme, http://www.publicservices.ac.uk/ wp-content/uploads/public-spending-in-hard-times.pdf, accessed 7 Jan 2010

Lawson, D. (2009) 'At Whose Service?', Sunday Times, 6 December
Mandelson, P. (2010) The Third Man: life at the heart of New Labour, London: Harper Press

National Audit Office (NAO) (2006) Progress in Improving Government Efficiency, report by the Comptroller and Auditor-General, HC802-1, session 2005-2006, 17 February 2006, London: The Stationery Office

NAO (2007) The Efficiency Programme: a second review of progress, report by the Comptroller and Auditor-General, HC156-1, session 2006-2007, 8 February 2007, London: The Stationery Office

NAO (2010a) Progress with Value For Money Savings and Lessons for Cost Reduction Programmes, report by the Comptroller and AuditorGeneral, HC291, session 2010-2011, London: The Stationery Office

NAO (2010b) Taking the Measure of Government Performance, report by the Comptroller and Auditor-General, HC284, session 2010-2011, London: The Stationery Office

NAO and Audit Commission (2006) Delivering Efficiently: strengthening the links in public service delivery chain, London: The Stationary Office

Norman, R. (2006) 'New Governance, New Dilemmas: post-reform issues in New Zealand's public sector', Policy Quarterly, 2 (3), pp.24-31

Norman, Z. (2008) 'Performance Budgeting in the United Kingdom', OECD Journal on Budgeting, 8 (1)

Office for Public Management (2007) Local Government Efficiency: case studies and literature review, London: Office for Public Management

PAC (House of Commons Committee of Public Accounts) (2006) Progress in Improving Government Efficiency: 55th report of session 2005-06 - report, together with formal minutes, oral and written evidence, 19 June 2006, London: The Stationery Office

PAC (2007) The Efficiency Programme: A Second Review of Progress: 48th report of session 2006-07 - report, together with formal minutes oral and written evidence, 9 July 2007, London: The Stationery Office 
PAC (2008) Managing Financial Resources to Deliver Better Public Services: 43rd report of Session 2007-08 - report, together with formal minutes, oral and written evidence, 23 June 2008, London: The Stationery Office

PAC (2010a) Progress with Value for Money Savings and Lessons for Cost Reduction Programmes, 4th report of session 2010-11 - report, together with formal minutes, oral and written evidence, 27 October 2010, London: The Stationary Office

PAC (2010b) Uncorrected Transcript of Oral Evidence: National Audit Office resources estimate for 2010, http://www.publications. parliament.uk/pa/cm200910/cmselect/cmpubacc/uc476-i/uc47602. htm, accessed 21 July 2010

Peters, B.G. (2008) 'Debate: the two futures of public administration', Public Money and Management, 28 (4), pp.195-6

Pollitt, C. (1986) 'Beyond the Managerial Model: the case for broadening performance assessment in government and the public services', Financial Accountability and Management, 2 (3), pp.155-70

Robinson, C. (2010) 'Managing for Efficiency: lessons for New Zealand from the UK's efficiency agenda 2004-2010', Master of Public Management dissertation, Victoria University of Wellington
Ryan, B., D. Gill, E. Eppel and M. Lips (2008) 'Managing for Joint Outcomes: connecting up the horizontal and the vertical', Policy Quarterly, 4 (3), pp.14-21

Scheers, B., M. Sterck and G. Bouckaert (2005) 'Lessons from Australian and British Reforms in Results-oriented Financial Management', OECD Journal on Budgeting, 5 (2), 133-62

State Services Commission (2009) Delivering Better Public Services, Wellington: State Services Commission

State Services Commission (2010a) Next Steps in Improving State Services Performance, Wellington: Office of the Minister of State Services

State Services Commission (2010b) Lifting the Performance and Service Delivery of State Sector Agencies, Wellington: Office of the Minister of State Services

Whitehead, J. (2009a) 'Public Sector Performance', speech to Victoria University School of Government, 20 July

Whitehead, J. (2009b) 'Public Sector Financial Management: stepping up to the challenge', speech to the Public Sector Financial Management conference, 10 December

Whitehead, J. (2010) 'Public Sector Performance', speech to public sector financial directors, 19 August
ANZSOG Annual Conference 2012

Museum of New Zealand Te Papa Tongarewa

Wellington, New Zealand. 24 - 26 July, 2012

\section{Future Proofing the State}

Risk, Responses and Resilience

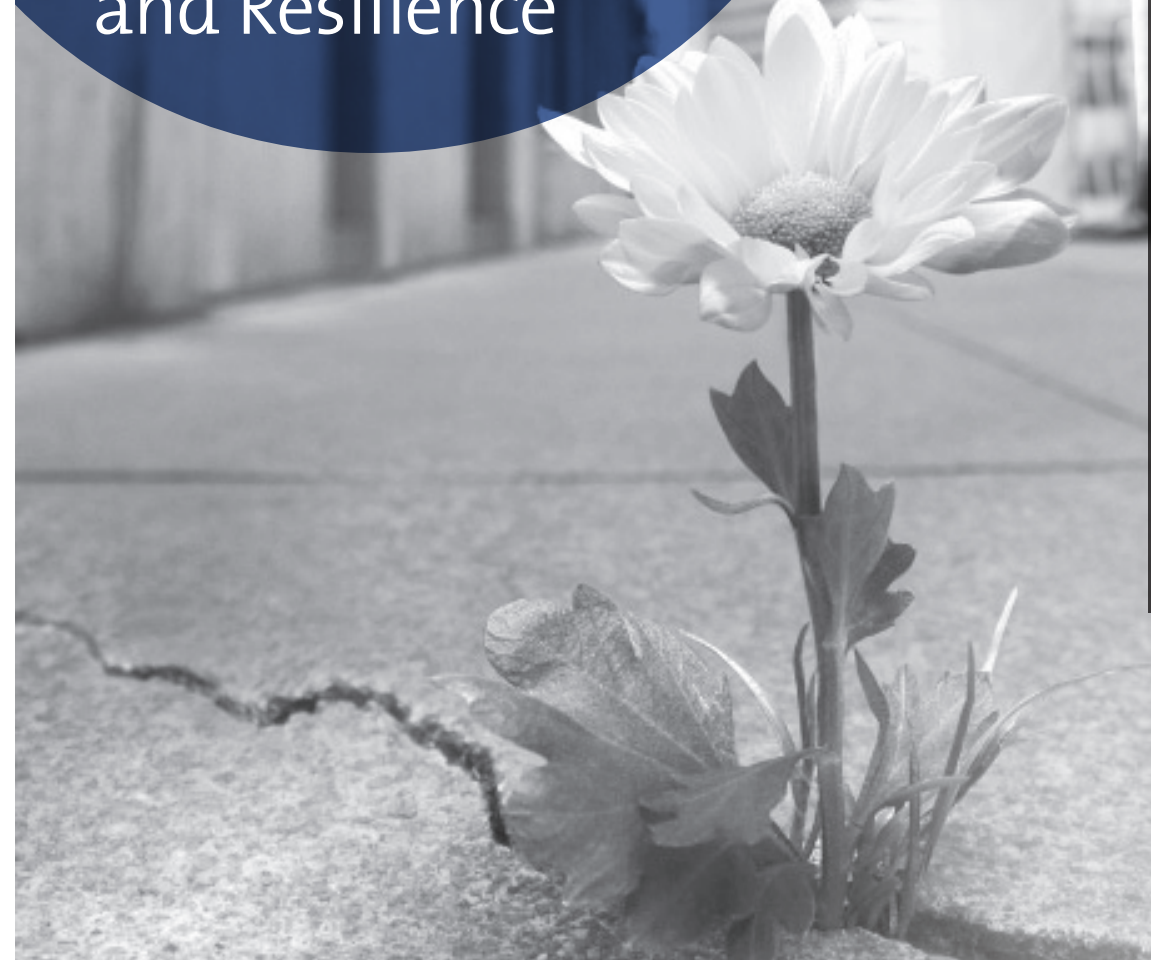

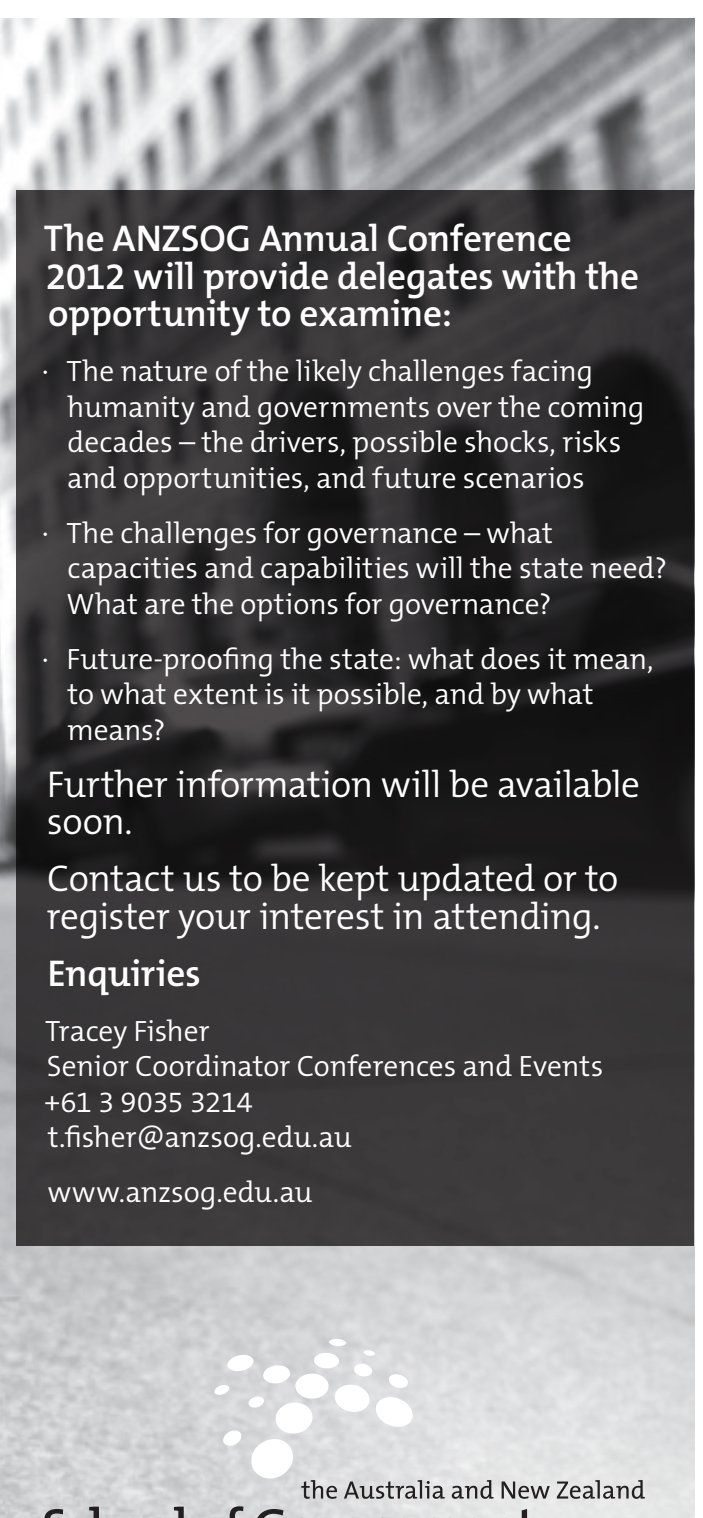

School of Government 